\title{
Plants Specifically Modulate the Microbiome of Root-Lesion Nematodes in the Rhizosphere, Affecting Their Fitness
}

\author{
Ahmed Elhady ${ }^{1,2, * \mathbb{D}}$, Olivera Topalović $^{1}$ and Holger Heuer ${ }^{1}$ (D) \\ 1 Institute for Epidemiology and Pathogen Diagnostics, Julius Kühn Institute (JKI)-Federal Research Centre \\ for Cultivated Plants, 38104 Braunschweig, Germany; otopalovic@agro.au.dk (O.T.); \\ holger.heuer@julius-kuehn.de (H.H.) \\ 2 Department of Plant Protection, Faculty of Agriculture, Benha University, Moshtohor 13736, Egypt \\ * Correspondence: ahmed.gomaa@julius-kuehn.de or ahmed.elhady1985@gmail.com
}

Citation: Elhady, A.; Topalović, O.;

Heuer, H. Plants Specifically

Modulate the Microbiome of Root-Lesion Nematodes in the Rhizosphere, Affecting Their Fitness. Microorganisms 2021, 9, 679. https:// doi.org/10.3390/microorganisms 9040679

Academic Editor: Ferenc Tóth

Received: 26 February 2021

Accepted: 22 March 2021

Published: 25 March 2021

Publisher's Note: MDPI stays neutral with regard to jurisdictional claims in published maps and institutional affiliations.

Copyright: (c) 2021 by the authors. Licensee MDPI, Basel, Switzerland. This article is an open access article distributed under the terms and conditions of the Creative Commons Attribution (CC BY) license (https:/ / creativecommons.org/licenses/by/ $4.0 /)$.
Abstract: Plant-parasitic nematodes are a major constraint on agricultural production. They significantly impede crop yield. To complete their parasitism, they need to locate, disguise, and interact with plant signals exuded in the rhizosphere of the host plant. A specific subset of the soil microbiome can attach to the surface of nematodes in a specific manner. We hypothesized that host plants recruit species of microbes as helpers against attacking nematode species, and that these helpers differ among plant species. We investigated to what extend the attached microbial species are determined by plant species, their root exudates, and how these microbes affect nematodes. We conditioned the soil microbiome in the rhizosphere of different plant species, then employed culture-independent and culture-dependent methods to study microbial attachment to the cuticle of the phytonematode Pratylenchus penetrans. Community fingerprints of nematode-attached fungi and bacteria showed that the plant species govern the microbiome associated with the nematode cuticle. Bacteria isolated from the cuticle belonged to Actinobacteria, Alphaproteobacteria, Betaproteobacteria, Gammaproteobacteria, Sphingobacteria, and Firmicutes. The isolates Microbacterium sp. i.14, Lysobacter capsici i.17, and Alcaligenes sp. i.37 showed the highest attachment rates to the cuticle. The isolates Bacillus cereus i.24 and L. capsici i.17 significantly antagonized P. penetrans after attachment. Significantly more bacteria attached to $P$. penetrans in microbiome suspensions from bulk soil or oat rhizosphere compared to Ethiopian mustard rhizosphere. However, the latter caused a better suppression of the nematode. Conditioning the cuticle of $P$. penetrans with root exudates significantly decreased the number of Microbacterium sp. i.14 attaching to the cuticle, suggesting induced changes of the cuticle structure. These findings will lead to a more knowledge-driven exploitation of microbial antagonists of plant-parasitic nematodes for plant protection.

Keywords: root-lesion nematode; suppressive soil; antagonistic microbes; rhizosphere; cuticle

\section{Introduction}

The root-lesion nematodes (RLN) from the genus Pratylenchus are migratory endoparasites feeding on a vast number of economical crops. RLN are among the most damaging plant-parasitic nematodes worldwide [1]. Depending on the Pratylenchus species, the life cycle lasts from three to nine weeks, with all life stages being migratory and infective. RLN reside inside roots or in the soil. Inside the root, they move intracellularly causing direct damage by lesions and feeding. This leads to wilting, yellowing, necrosis, and increased susceptibility to secondary diseases [2]. While searching for a suitable host or surviving adverse conditions, these nematodes migrate through soil where they are exposed to a great variety of microorganisms. Depending on the nature of plant-nematode-microbe interactions in soil, plants may be protected by specific mutualistic microbes [3-5]. The term "holobiont" defines a macroorganism (plant or animal) as a unit that includes all its associated (micro)organisms [6,7]. The functioning of a macroorganism highly depends on its core microbiota [8]. As for the plant holobiont, it is still difficult to discern the role of the 
plant per se and the surrounding soil in shaping the microbial community that is selectively associated to the plant root. It has been suggested that the influence of roots on microbial diversity in soil varies across different soil compartments, being lower in diversity in the rhizosphere than in bulk soil $[9,10]$. The effects of the different plant host rhizospheres and the bulk soil microbiome against phytonematode attack were recently tested, and it was concluded that the rhizospheric microbes had a higher potential to protect plants from Pratylenchus penetrans and Meloidogyne incognita than the microbes residing in the bulk soil [11]. Furthermore, it was shown that in the case of tomato and soybean plants, the microbiome of the plant was more efficient than bulk soil in reducing nematode invasion into the roots [11], suggesting a well-established role of beneficial microbes in the plant holobiont [8]. Soil type plays an important role in shaping the diversity and richness of bacterial communities in soil [12], but the activity and the biomass of soil microorganisms in the rhizosphere is determined by root exudations [13]. Root exudates represent ions, enzymes, mucilage, and other low and high molecular weight molecules [14]. They may directly affect the microbe-nematode interactions in soil and be involved in plant defense against certain pathogens and parasites [15].

There is a specific microbial attachment to phytonematodes in the soil that is dependent on the nematode species and the soil type [16,17]. It was suggested that, besides directly antagonizing their nematode carriers, nematode-attached microbes can trigger plant defense responses against the attack of a plant-parasitic nematode [3]. The surface coat (SC) is the outermost glycoprotein layer that covers the nematode cuticle [17]. The SC is directly involved in the microbial attachment [18]. It was shown that nematodes change SC composition in response to environmental changes, which can lead to their protection against antagonizing microbes $[19,20]$.

In the current study, we aimed to investigate how the factors that contribute to the establishment of a plant holobiont, also contribute to the establishment of a nematode holobiont. We hypothesized that nematodes engage in a prolonged dialogue with their host plants directly prior to the invasion at the soil-root interface, where roots are always enriched with specific taxa of microorganisms and different molecules. This determines the microbiome associated with their bodies, which shifts among different host plants and affects their fitness. To test our hypothesis, we employed culture-independent and culture-dependent methods to study the microbial attachment to P. penetrans in two different soil types, and compared the attachment preferences of microbiomes residing in the rhizospheres of maize, soybean, Ethiopian mustard, oat, and tomato plants to the attachment of the microbiome from bulk soil. Nematode-attached bacteria were isolated and identified. In addition, the effects of the attached soil microbiome and single bacterial isolates were tested against nematode mortality and motility in vitro. As it was shown that the root exudates of different plants affect the attachment of Pasteuria spores to root-knot nematodes [21,22], and can directly affect changes in nematode gene expression [23,24], we also studied whether the root exudates affect changes in the attachment of soil microbes or single bacterial isolates to P. penetrans.

\section{Materials and Methods}

\subsection{Preparation of Nematodes}

Fresh mixed stages of $P$. penetrans were extracted from a 2-month axenic carrot disc culture using a Baermann funnel and surface-sterilized according to Elhady et al. [11]. Briefly, nematodes were washed over $5-\mu \mathrm{m}$ sieves with $10 \mathrm{~mL}$ of sterilized tap water and incubated in $0.02 \% \mathrm{HgCl}_{2}$ for $3 \mathrm{~min}$, followed by incubation in $5 \mathrm{~mL} 1 \times \mathrm{CellCultureGuard}$ (AppliChem, Darmstadt, Germany) for four hours. Nematodes were recovered on sterile 5 - $\mu \mathrm{m}$ sieves (Cell-Trics1 filters, Sysmex, Norderstedt, Germany), washed with $10 \mathrm{~mL}$ of sterile tap water, and incubated for $48 \mathrm{~h}$ in sterile tap water to renew their cuticle, followed by another washing step over sterile $5-\mu \mathrm{m}$ sieves to wash out the debris of the old cuticle directly before the use in experiments. 


\subsection{Experimental Design: Microbiome Associated with RLN as Affected by Plant Species}

We tested whether the plant species governs the microbiome associated with the RLN cuticle in two independent experiments.

\subsubsection{Preparation of Rhizosphere and Bulk Soil Suspensions}

In the first experiment, the rhizosphere microbiome was obtained from different plant hosts, maize (Zea mays L. cv. Colisee), soybean (Glycine max L. cv. Primus), and tomato (Solanum lycopersicum L. cv. Moneymaker). The plants were grown in 12-cm diameter plastic pots filled with $500 \mathrm{~mL}$ of field soil (less sandy loam with 1.4\% humus, pH 6.2; $\left.52^{\circ} 17^{\prime} 57^{\prime \prime} \mathrm{N}, 10^{\circ} 26^{\prime} 14^{\prime \prime} \mathrm{E}\right)$. The bulk soil was obtained in the same way, without growing a host plant. In the second experiment, soil suspensions from the rhizospheres of maize, Ethiopian mustard (Brassica carinata cv. Cappuccino), and oat (Avena strigosa cv. Luxurial) plants grown in field soil (sandy loam, pH 6.3; 52 $16^{\prime} 21.7^{\prime \prime} \mathrm{N} 10^{\circ} 34^{\prime} 02.7^{\prime \prime} \mathrm{E}$ ) were obtained in the same way to study the attachment of bacteria and fungi to P. penetrans in this soil. The pots of both experiments were irrigated and fertilized using $2.5 \mathrm{~g} \mathrm{~L}^{-1}$ of a commercial fertilizer (WUXAL Super NPK fertilizer, 8-8-6 with micronutrients, AGLUKON, Düsseldorf, Germany), and kept for 6 weeks in the greenhouse at $24{ }^{\circ} \mathrm{C}$ and with a $16: 8 \mathrm{~h}$ photoperiod. To extract the microbiome, $5 \mathrm{~g}$ of roots with attached soil or bulk soil was blended in a Stomacher blender (Seward, London, UK) with $15 \mathrm{~mL}$ of sterile $0.85 \% \mathrm{NaCl}$ at high speed for $60 \mathrm{~s}$ to efficiently release the microbes into the suspension. The supernatants were sieved through $5-\mu \mathrm{m}$ sieves to remove mesofauna, root debris, and remaining soil particles.

\subsubsection{Baiting of Soil Microbes Attaching to the Cuticle of P. penetrans}

Baiting of microbes from the rhizosphere or bulk soil suspensions on the cuticle of $P$. penetrans was done as previously described [25]. Briefly, 20,000 surface-sterilized nematodes were incubated in $5 \mathrm{~mL}$ of each microbial suspension in $15 \mathrm{~mL}$ tubes. The tubes were positioned horizontally on a shaker at a speed of $150 \mathrm{rpm}$ at $20 \pm 2{ }^{\circ} \mathrm{C}$ for $24 \mathrm{~h}$. The nematodes with attached microbes were recovered on $5-\mu \mathrm{m}$ sieves and washed with $20 \mathrm{~mL}$ of sterile tap water to remove loosely attached microbes. To isolate the attached bacterial strains, nematodes were plated on R2A media (Merck, Germany) supplemented with $10 \mathrm{mg} \mathrm{L}^{-1}$ cycloheximide. The plates were incubated at $28^{\circ} \mathrm{C}$ and bacterial strains were collected from the emerged colonies over a 2-week period. A portion of the nematodes with attached microbes was transferred to bead-beating tubes with Lysing Matrix E (MP Bio, Heidelberg, Germany) for DNA extraction.

2.2.3. Denaturing Gradient Gelelectrophoresis (DGGE) Profiling of Nematode-Attached Microbiomes

Total DNA from P. penetrans and their associated microbes was extracted using the Fastprep FP120 bead beating system for $30 \mathrm{~s}$ at a high speed and a FastDNA Spin Kit for Soil (MP Bio, Heidelberg, Germany). The DGGE profiling of the nematode-attached microbiome was done according to Adam et al. [16]. The bacterial 16S rRNA fragments from low DNA concentrations were amplified by nested-PCR, using in the first PCR the primer pair S-D-Bact-0008-a-S-16/S-D-Bact-1492-a-A-16, followed by a second PCR using the primer pair F984GC/R1378 [26]. The fungal internal transcribed spacers (ITS) were amplified in a nested PCR approach using the primer pairs ITS1F/ITS4 and ITS1FGC/ITS2 [27]. DGGE was done using the PhorU2 system (Ingeny, Goes, The Netherlands) according to Weinert et al. [27]. The software GelCompar II v. 6.6 (Applied Maths, Sint-Martens-Latem, Belgium) was used to analyze the DGGE profiles. The resulting Pearson similarity matrices were used for a permutation test on significant differences among the microbial communities [28]. Some of the bacterial and fungal bands were identified by the cloning of PCR products using the vector PGEM-T and Escherichia coli JM109 high-efficiency competent cells (Promega, Madison, WI, USA), and sequencing with vector primers T7 and SP6 (Macrogen, Amsterdam, The Netherlands). The sequences of fungal and bacterial clones, 
as well as isolates, were deposited in NCBI GenBank with accession numbers MN332046 to MN332063, and MW326933 to MW326970.

\subsubsection{Characterization of Bacterial Isolates}

Morphologically different nematode-attached bacterial isolates were purified twice to obtain pure isolates. To isolate the DNA from bacterial isolates, bacterial cells were lysed by adding $100 \mu \mathrm{L}$ of $50 \mathrm{mM}$ Tris- $\mathrm{HCl} \mathrm{pH}$ 8.0/50 mM EDTA/0.5\% Tween 20/0.5\% Triton X-100, containing $200 \mu \mathrm{g}$ lysozyme, $90 \mu \mathrm{g}$ proteinase $\mathrm{K}$, and $20 \mu \mathrm{g}$ RNase A. After a 30 min-incubation at $37^{\circ} \mathrm{C}, 3 \mathrm{M}$ guanidine hydrochloride/20\% tween 20 was added, and the lysate was incubated at $50{ }^{\circ} \mathrm{C}$ for $30 \mathrm{~min}$. A $200 \mu \mathrm{L}$ suspension of GeneClean Spin Glassmilk (MP Bio) was added to capture DNA from the lysate. The pelleted Glassmilk was washed twice with $500 \mu \mathrm{L}$ washing solution $(100 \mathrm{mM} \mathrm{NaCl} / 1 \mathrm{mM}$ EDTA/10 mM Tris- $\mathrm{HCl}$, pH 7.5/50\% EtOH). The DNA was air-dried for $10 \mathrm{~min}$ and eluted with $100 \mu \mathrm{L}$ $10 \mathrm{mM}$ Tris- $\mathrm{HCl} / 0.1 \mathrm{mM}$ EDTA pH 8.0. The supernatant containing DNA was separated from the Glassmilk by centrifugation at a maximum speed for $2 \mathrm{~min}(12,000 \times g)$ and stored at $-20{ }^{\circ} \mathrm{C}$ until use. Discrimination of isolates to identify unique strains was performed by BOX-PCR fingerprinting [29]. From ca. $20 \mathrm{ng}$ of template DNA, genomic fragments were amplified in a $25 \mu \mathrm{L}$ PCR reaction using GoTaq Flexi Buffer, $3.75 \mathrm{mM} \mathrm{MgCl}$, $0.2 \mathrm{mM}$ of each dNTP, 5\% w/v DMSO, $0.2 \mu \mathrm{M}$ primer BOXA1R (5'-CTA CGG CAA GGC GAC GCT GAC TGA CG-3'), and 1 U GoTaq Flexi DNA polymerase (Promega). PCR conditions were as follows: denaturation step for $7 \mathrm{~min}$ at $94{ }^{\circ} \mathrm{C}, 35$ cycles of $1 \mathrm{~min}$ at $94{ }^{\circ} \mathrm{C}, 1 \mathrm{~min}$ at $53{ }^{\circ} \mathrm{C}$, and $8 \mathrm{~min}$ at $65^{\circ} \mathrm{C}$, and a final extension step for $16 \mathrm{~min}$ at $65^{\circ} \mathrm{C}$. The PCR bands were separated by $1.5 \%$ agarose gel electrophoresis for $3 \mathrm{~h}$ at $80 \mathrm{~V}$ and visualized by UV transillumination $(254 \mathrm{~nm}$ ) after staining with ethidium bromide. The band patterns of the bacterial isolates were compared by GelCompar II 6.6 (Applied Maths, Sint-Martens-Latem, Belgium), and twenty different isolates were selected for further investigations.

\subsection{Biological Effects of the Nematode-Attached Microbiome}

To study whether the microbiome that attaches to $P$. penetrans affects nematode viability, soil suspensions were prepared from bulk soil and the rhizospheres of Ethiopian mustard, maize, and oat. For preparation of soil suspensions, $10 \mathrm{~g}$ of soil or roots with adhering rhizosphere soil were blended using a Stomacher 80 blender (Seward) in $2 \times 20 \mathrm{~mL}$ of sterile tap water for $1 \mathrm{~min}$ at a high speed. Soil particles were spun down for $5 \mathrm{~min}$ at $500 \times g$ and the supernatant was sieved through a sterile $5 \mu \mathrm{m}$ sieve (Cell-Trics1 filters, Sysmex, Norderstedt, Germany). The flow-through was pelleted for $10 \mathrm{~min}$ at $5000 \times g$ and the pellet re-suspended in $6 \mathrm{~mL}$ of sterile tap water. Around 4000 surface-sterilized nematodes were incubated in $4 \mathrm{~mL}$ of soil suspensions or sterile tap water as a control at low shaking speed overnight. The next day, nematodes were recovered on $5-\mu \mathrm{m}$ sieves and washed with $15 \mathrm{~mL}$ sterile tap water to remove loosely attached microbes. A subset of 100 washed nematodes, with or without attached microbiome, was incubated for 5 days in sterile tap water to assess nematode viability. To determine the number of attached bacteria per worm, nematodes were plated on R2A media supplemented with $10 \mathrm{mg} / \mathrm{L}$ cycloheximide. The R2A plates were kept at $28^{\circ} \mathrm{C}$ for 2 days before counting colony-forming units (CFU).

To study the effects of single bacterial isolates on nematode mortality, bacterial cultures of isolates i1- i55 (Table 1) were grown from $100 \mu \mathrm{L}$ pre-culture in $25 \mathrm{~mL}$ LB broth (Luria/Miller-Carl Roth, Karlsruhe, Germany) for $24 \mathrm{~h}$ at $28^{\circ} \mathrm{C}$ with shaking. Strains Rhizobium etli G12 and E. coli JM109 were used as positive and negative controls, respectively. Bacterial cultures were centrifuged at $4000 \times g$ for $15 \mathrm{~min}$ to obtain the bacterial cells. Later, pellets of bacterial cells were re-suspended in $1 \mathrm{~mL} 0.85 \% \mathrm{NaCl}$ and the concentration was adjusted to $0.2 \mathrm{OD}_{600 \mathrm{~nm}}$. A volume of $50 \mu \mathrm{L}$ sterile suspension comprising 500 nematodes was added to $2 \mathrm{~mL}$ of bacterial suspensions in 24-well plates (Carl Roth, Karlsruhe, Germany). The 24-well plates were incubated at $20 \pm 2{ }^{\circ} \mathrm{C}$ with slow shaking. Live and dead nematodes were evaluated using a stereomicroscope (Olympus Microscope SZX12) after $48 \mathrm{~h}$. 
Table 1. Taxonomic assignment of bacterial strains that were isolated from the cuticle of Pratylenchus penetrans after baiting in suspensions of bulk soil or different rhizosphere soils.

\begin{tabular}{cccc}
\hline Isolate & Source & Most Similar Sequence, Accession No. & Identity \\
\hline i.1 & Bulk soil & Streptomyces violaceoruber, NR_112292.1 & $99 \%$ \\
i.3 & Bulk soil & Streptomyces atratus, NR_043490.1 & $100 \%$ \\
i.4 & Bulk soil & Bacillus marisflavi, NR_118437.1 & $99 \%$ \\
i.7 & Bulk soil & Nocardia coeliaca, NR_104776.1 & $99 \%$ \\
i.9 & Bulk soil & Mycobacterium madagascariense, NR_104690.1 & $99 \%$ \\
i.13 & Bulk soil & Microbacterium maritypicum, NR_114986.1 & $99 \%$ \\
i.14 & Bulk soil & Microbacterium mangrovi, NR_126283.1 & $99 \%$ \\
i.16 & Bulk soil & Delftia tsuruhatensis, NR_113870.1 & $99 \%$ \\
i.17 & Bulk soil & Lysobacter capsici, NR_044250.1 & $100 \%$ \\
i.23 & Maize rhizosphere & Novosphingobium aquaticum, NR_148323.1 & $99 \%$ \\
i.24 & Maize rhizosphere & Bacillus cereus, NR_074540.1 & $99 \%$ \\
i.26 & Maize rhizosphere & Pedobacter borealis, NR_044381.1 & $99 \%$ \\
i.27 & Maize rhizosphere & Pseudomonas protegens, NR_114749.1 & $99 \%$ \\
i.35 & Soybean rhizosphere & Bacillus megaterium, NR_116873.1 & $100 \%$ \\
i.37 & Soybean rhizosphere & Alcaligenes faecalis, NR_113606.1 & $99 \%$ \\
i.42 & Soybean rhizosphere & Rhizobium nepotum, NR_117203.1 & $99 \%$ \\
i.47 & Soybean rhizosphere & Bacillus megaterium, NR_116873.1 & $99 \%$ \\
i.50 & Soybean rhizosphere & Mycobacterium chubuense, NR_041902.1 & $99 \%$ \\
i.55 & Soybean rhizosphere & Bacillus aryabhattai, NR_115953.1, & $100 \%$ \\
i.63 & Tomato rhizosphere & Staphylococcus capitis, NR_113348.1 & $100 \%$ \\
\hline
\end{tabular}

\subsection{Effects of Root Exudates on Microbial Attachment to Nematodes}

To obtain root exudates, the seeds of maize, soybean, and tomato were surface sterilized using $1.5 \%$ sodium hypochlorite for $15 \mathrm{~min}$ and rinsed five times with sterile deionized water. The seeds were planted in sterile jars containing $1 / 2$ strength MS media (Murashige and Skoog medium including vitamins, DUCHEFA BIOCHEMIE, Netherlands) and maintained in a growth chamber for 2 weeks at $22{ }^{\circ} \mathrm{C}(65 \%$ humidity and $16 \mathrm{~h}$ photoperiod). To collect the root exudates, plants were carefully removed from the growth substrate. The roots were gently washed and incubated in $50 \mathrm{~mL}$ of sterile water in glass jars. After $48 \mathrm{~h}$, the released root exudates were collected, filter-sterilized through a $0.2-\mu \mathrm{m}$ filter (Minisart, Sartorius Stedim biotech, Göttingen, Germany) and stored at $-20^{\circ} \mathrm{C}$ until use.

To test the effects of root exudates on microbial attachment to P. penetrans, around 5000 surface-sterilized nematodes were incubated in $2 \mathrm{~mL}$ of root exudates of soybean, maize, tomato, or $1 \mu \mathrm{M} \alpha$-naphthalene acetic acid (NAA, Duchefa Biochemie, Netherlands) and sterile tap water as control in 6-well plates (Carl Roth, Karlsruhe, Germany) at $20 \pm 2{ }^{\circ} \mathrm{C}$ overnight with slow shaking. The following day, $2 \mathrm{~mL}$ of the bulk soil suspension was added to each well and the incubation continued overnight. After incubation, nematodes were recovered on $5-\mu \mathrm{m}$ sieves and washed with $15 \mathrm{~mL}$ of sterile tap water to remove loosely attached microbes. Nematodes with attached microbes were transferred to beadbeating tubes and stored at $-20^{\circ} \mathrm{C}$ until DNA extraction.

To test if root exudate-induced changes of the nematode cuticle affect attachment of bacterial isolates, $2 \mathrm{~mL}$ microtubes containing 500 nematodes in $500 \mu \mathrm{L}$ of soybean, maize, or tomato root exudates were incubated at $20 \pm 2{ }^{\circ} \mathrm{C}$ with slow shaking overnight. Incubations in sterile tap water and $1 \mu \mathrm{M}$ NAA solution served as controls. The following day, nematodes were spun down in $1.5 \mathrm{~mL}$ microtubes at $1000 \times g$ for $2 \mathrm{~min}$, and the supernatant was replaced with $250 \mu \mathrm{L}$ of the bacterial strain i.14 and $250 \mu \mathrm{L}$ of the bacterial strain i.14-Rif as a reference. Nematodes were additionally incubated in bacterial suspensions overnight. Non-attached bacterial cells were separated from the nematodes by centrifugation at $1000 \times g$ for $1 \mathrm{~min}$ at room temperature. The supernatant was discarded and the nematode pellet was washed twice by centrifugation with $1 \mathrm{~mL}$ of sterile tap water. Nematodes with attached bacterial cells were re-suspended in $1 \mathrm{~mL}$ of sterile tap water by adding $0.2 \mathrm{~g}$ of $0.1 \mathrm{~mm}$ glass beads and vortexing for $10 \mathrm{~s}$. To determine the number of 
attached bacterial CFU per nematode, these were serially diluted and plated on R2A media. The plates were kept at $28^{\circ} \mathrm{C}$ and the CFU were counted after $48 \mathrm{~h}$.

\subsection{Data Analysis and Statistics}

The GENMOD procedure from the package SAS 9.4 (SAS Institute Inc., Cary, NC, USA) was used to analyze count data. It was performed with Poisson distribution, log link function, and specification of a scale parameter (Pearson) to account for overdispersed data. For multiple comparisons to a control, the alpha level was adjusted according to Dunnett. For multiple comparisons, the Tukey's significant post hoc test was used to obtain significant differences represented in letters. For the non-metric multidimensional scaling (NMDS), Pearson correlations of background-subtracted densitometric curves from the DGGE analysis were processed using the R package Vegan. The DGGE community profiles were compared using software GelCompar II 6.6 (Applied Maths, Sint-Martens-Latem, Belgium). Pearson correlation for calculating similarity coefficient values per lane was used for clustering based on the unweighted pair group method with arithmetic mean (UPGMA) and to perform permutation tests for significant differences among nematode associated microbes from the different rhizosphere and bulk soils, and to calculate the d-value that indicates the difference in average similarities within and among groups according to Kropf et al. [28].

\section{Results}

\subsection{Rhizosphere Fungi Attaching to P. penetrans Depended on Plant Species}

PCR-DGGE fingerprinting of fungal ITS and bacterial 16S rRNA gene fragments was used to compare the microbial communities that specifically attached to P. penetrans in the rhizosphere of different plant species or in bulk soil. Two independent experiments were performed, with tomato, maize, and soybean in the first experiment, and with maize, oat, and Ethiopian mustard in the second experiment. The fungal species attaching to P. penetrans differed significantly among the rhizospheres of the plant species $(p<0.001, n=4$, constrained permutation test based on pairwise Pearson correlations of the PCR-DGGE fingerprints; Figure 1). The cuticle-attached fungal communities in the rhizosphere differed among plants by $43-87 \%$ in the first experiment, and $3-29 \%$ in the second experiment (Table 2). The fungal communities attaching to P. penetrans cuticle from maize and tomato rhizosphere were most dissimilar, while in the rhizosphere of oat and Ethiopian mustard the fungal communities attaching to the cuticle were highly similar. Moreover, the results revealed a significant difference of the cuticle-attached fungal communities between rhizospheres and bulk soil ( $p<0.001)$, however, these communities from rhizospheres differed more from those from bulk soil than among rhizospheres of the different plants (Table 2). The dissimilarity of nematode-associated fungal communities between bulk soil and rhizospheres was $62 \%$ to $88 \%$, and $10 \%$ to $28 \%$ in the first and second experiment, respectively (Table 2). The abundant soil fungi that were not attached to the cuticle significantly differed among rhizospheres and between bulk soil and rhizosphere soils $(p<0.001$, Table S1). The abundant fungi in soil were more diverse than cuticle-attached fungi (Figure S1 compared to Figure 1), and the fungal communities in soil were distinct from those on the nematodes, as shown by NMDS (Figure 2). 


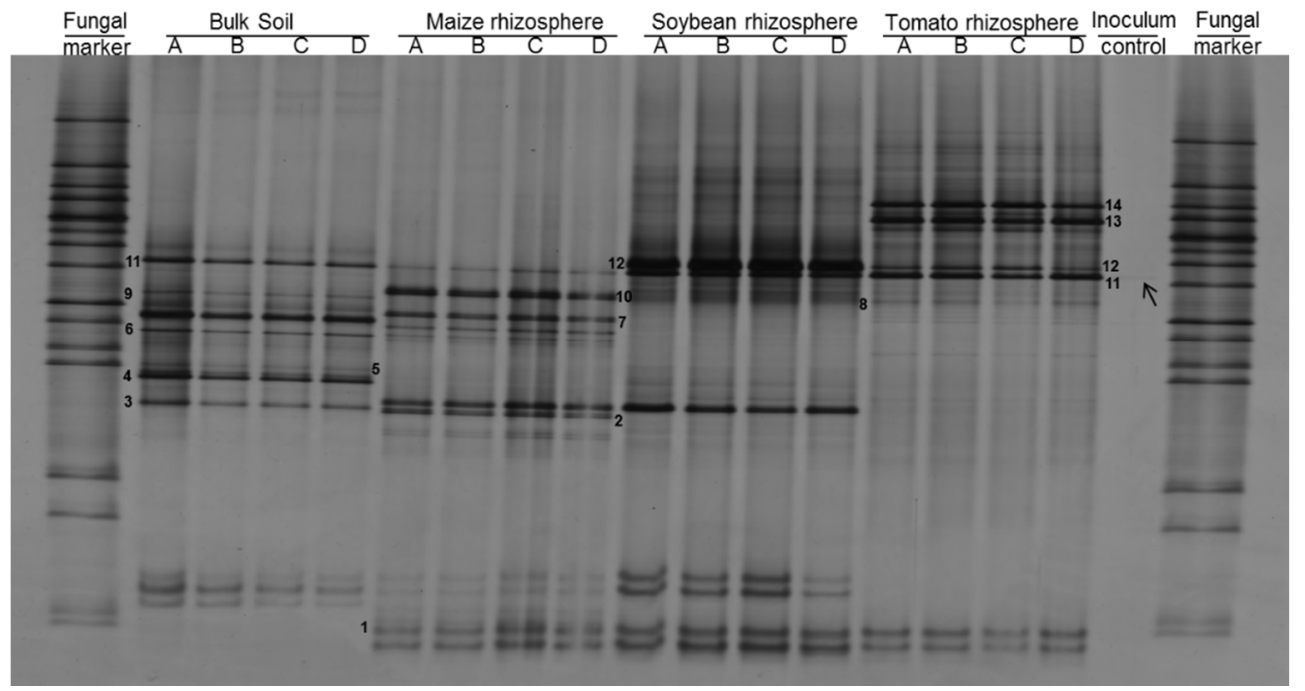

Figure 1. Denaturing gradient gelelectrophoresis (DGGE) profiles of fungal internal transcribed spacer (ITS) fragments amplified from DNA of Pratylenchus penetrans incubated in suspensions of bulk soil and rhizosphere soils (Experiment 1). Letters A, B, C, and D represent biological replicates. Surface-sterilized nematodes prior to incubation are referred to as inoculum control. Numbers 1-14 represent the bands that were taxonomically assigned by DNA sequencing and that showed specificity of fungal species in their attachment to P. penetrans.

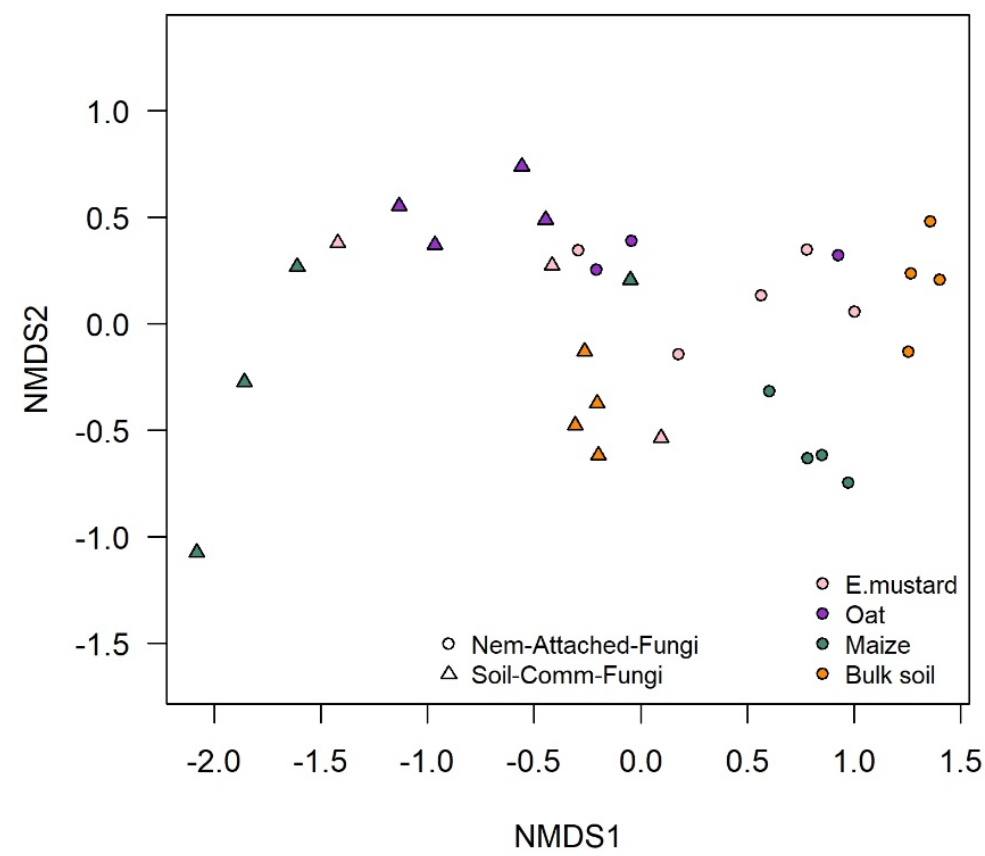

Figure 2. Effect of plant species on soil and P. penetrans attached fungi. Non-metric multidimensional scaling (NMDS) plots are presented based on Pearson correlations of background-subtracted densitometric curves from denaturing gradient gelelectrophoresis (DGGE). Stress value is 0.031, $n=4$.

In the first experiment, the fungal fingerprints showed 14 distinct bands (Figure 1). One fungal type was associated to the nematodes in all the treatments (band no. 11 in Figure 1). The DNA of the band was sequenced and assigned to Cladosporium tenuissium with 99\% identity (Table S2). This fungus was the most abundant on the cuticle after incubation of the nematodes in soybean and tomato rhizosphere soil suspensions (Figure 1). The band was also detectable in the nematode inoculum after surface-sterilization, but with 
a very low intensity. The fungal type identified as Malassezia restricta with $99 \%$ identity (band no. 1, Figure 1) attached to P. penetrans in the rhizosphere soil suspensions of all three plants, but not in the bulk soil suspension. Although several nematode-attached fungal types were shared between nematodes from two different treatments (bands no. 2, 6, and 12; Figure 1 and Table S2), most attached fungi exhibited a high specificity for one of the rhizospheres. For instance, the fungal bands assigned to Myrothecium verrucaria with 99\% identity (band no. 7) and Aspergillus tonophilum with 100\% (band no. 10) identity were associated with $P$. penetrans only after incubation in the suspension of the maize rhizosphere. Other fungi attached to the nematodes only in the suspension of tomato rhizosphere soil: band no. 8, identified as Penicillium alli, P. gladioli, and P. hordei; band no. 13 identified as Sporidiobolus pararoseus; and band no. 14 assigned to Cutaneotrichosporon curvatus (Table S2).

Table 2. Percent dissimilarity of cuticle-attached bacterial or fungal communities after incubation of P. penetrans in suspensions of rhizosphere soils or bulk soil, based on denaturing gradient gelelectrophoresis (DGGE).

\begin{tabular}{|c|c|c|c|}
\hline \multirow{2}{*}{\multicolumn{2}{|c|}{$\begin{array}{l}\text { Sources of Soil Suspensions for Pairwise Comparison of DGGE Fingerprints } \\
\text { of Nematode-Attached Bacteria or Fungi }\end{array}$}} & \multicolumn{2}{|c|}{ Dissimilarity (\%) ${ }^{a}$} \\
\hline & & \multirow{2}{*}{$\frac{\text { Bacteria }}{23}$} & \multirow{2}{*}{$\frac{\text { Fungi }}{62}$} \\
\hline \multirow{6}{*}{ 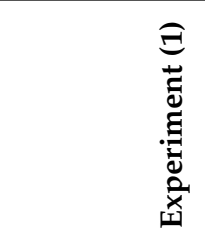 } & Bulk soil vs. maize rhizosphere & & \\
\hline & Bulk soil vs. tomato rhizosphere & 35 & 88 \\
\hline & Bulk soil vs. soybean rhizosphere & 40 & 65 \\
\hline & Maize vs. tomato rhizosphere & 43 & 87 \\
\hline & Maize vs. soybean rhizosphere & 51 & 43 \\
\hline & Soybean vs. tomato rhizosphere & 68 & 57 \\
\hline \multirow{6}{*}{ 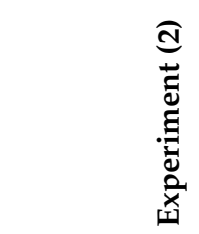 } & Bulk soil vs. maize rhizosphere & 34 & 14 \\
\hline & Bulk soil vs. oat rhizosphere & 31 & 28 \\
\hline & Bulk soil vs. Ethiopian mustard rhizosphere & 12 & 10 \\
\hline & Maize vs. oat rhizosphere & 29 & 29 \\
\hline & Maize vs. Ethiopian mustard rhizosphere & 36 & 17 \\
\hline & Oat vs. Ethiopian mustard rhizosphere & 22 & 3 \\
\hline
\end{tabular}

a d-value: average of pairwise Pearson correlation coefficients among DGGE fingerprints within each group minus the average of pairwise Pearson correlation coefficients among DGGE fingerprints of different groups.

\subsection{Rhizosphere Bacteria Attaching to P. penetrans Depended on Plant Species}

Similarly to what we observed for fungi, the bacterial attachment to P. penetrans in rhizosphere soil suspensions was plant-specific in the two experiments $(p=0.032$ for experiment $1 ; p=0.018$ for experiment 2). The bacterial DGGE profiles comprised 19 bands of cuticle-attached bacteria in the rhizosphere and 12 bands in bulk soil (Figure 3). Three bacterial types were commonly associated with P. penetrans in bulk soil and in the maize and soybean rhizospheres (Figure 3): band no. 6, assigned to Bradyrhizobium embrapense with 95\% identity; band no. 8, assigned to Pseudomonas synxantha; and band no. 12, assigned to Streptococcus himalayensis (Table S2). However, few other bands were common among treatments supporting a very specific association between nematodes and bacteria in each rhizosphere soil: Streptococcus rubneri (band 9) and Moraxella nonliquefaciens (band 13) were exclusively detected on the nematode's cuticle after incubation in the suspension of tomato rhizosphere soil; Paraburkholderia dipogenis (band 1) was specifically associated with nematodes in soybean rhizosphere suspension. 


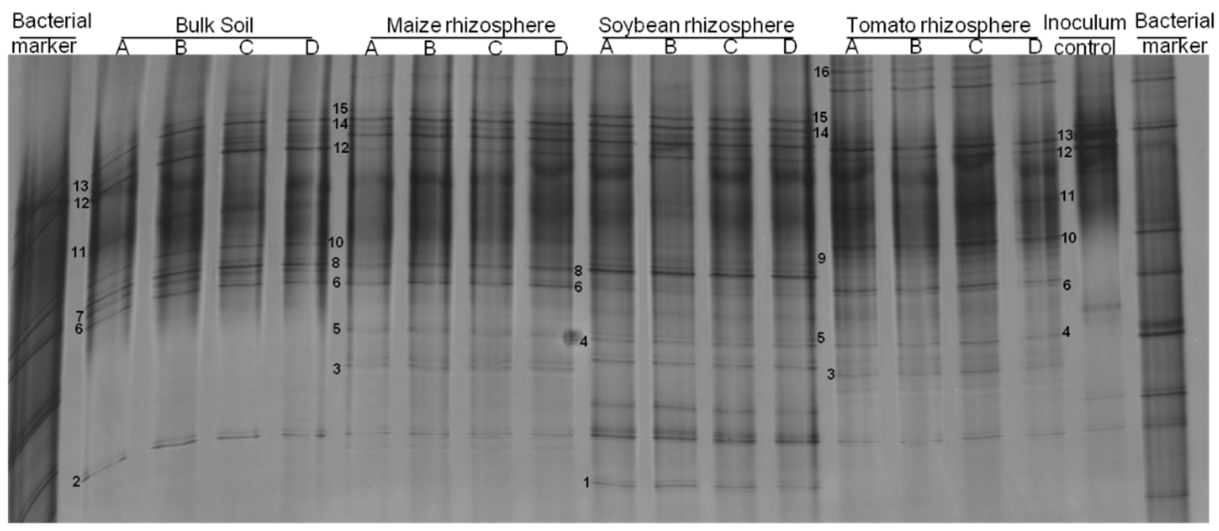

Figure 3. Denaturing gradient gelelectrophoresis (DGGE) profiles of bacterial 16S rRNA fragments amplified from DNA of Pratylenchus penetrans incubated in microbial suspensions of bulk soil and the rhizospheres of maize, soybean, and tomato plants grown in the same soil (Experiment 1). Letters A, B, C, and D represent biological replicates. Surface-sterilized nematodes prior to incubation are referred to as inoculum control. Numbers 1-15 represent bands that were taxonomically assigned by DNA sequencing and that showed specificity of bacterial species in their attachment to P. penetrans.

The abundant bacteria in soil were much more diverse than cuticle-attached bacteria (Figure S2 compared to Figure 3). The bacterial communities in soil were distinct from those attached to the nematodes, as shown by NMDS (Figure 4). The cuticle-attached bacterial communities in the rhizosphere differed among plants by $43-68 \%$ in the first experiment, and $22-36 \%$ in the second experiment (Table 2). The community attached to P. penetrans from soybean and tomato rhizosphere were most dissimilar, while in the rhizosphere of oat and Ethiopian mustard the bacterial communities attaching to the cuticle were most similar. It also differed between rhizospheres and bulk soil $(p<0.001)$. The dissimilarity of nematode associated bacterial communities between bulk soil and rhizospheres was $23 \%$ to $40 \%$, and $12 \%$ to $34 \%$ in the first and second experiment, respectively (Table 2). The abundant soil bacteria that were not attached to the cuticle significantly differed among rhizospheres and between bulk soil and rhizosphere soils $(p<0.001$, Table S1). The differences among the microbial communities that attached to nematodes in the different soils and the non-attached microbial communities were not well correlated (Table S1).

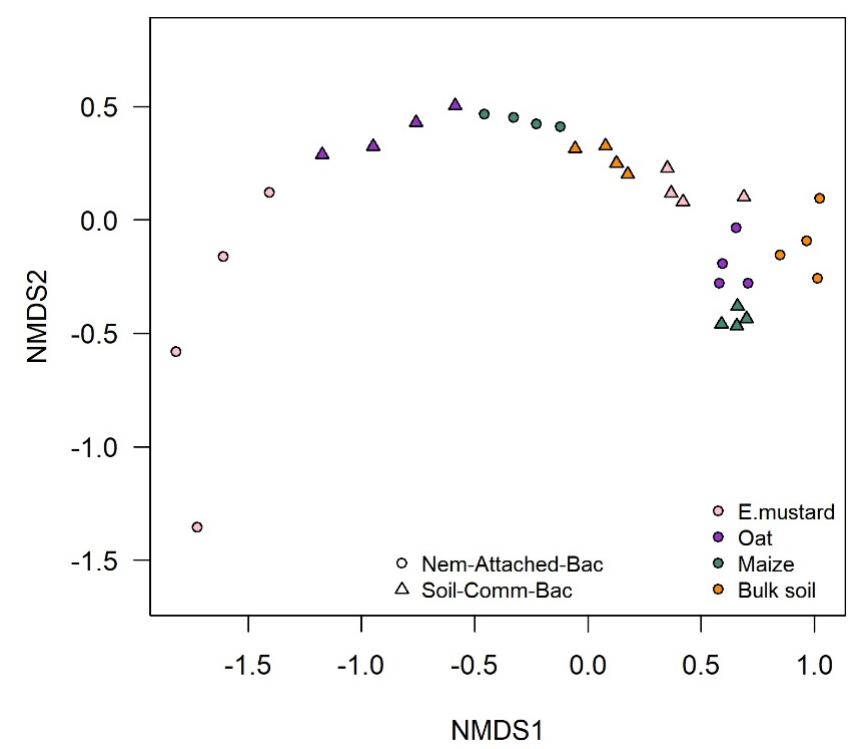

Figure 4. Effect of plant species on soil and P. penetrans attached bacterial communities. Non-metric multidimensional scaling (NMDS) plots are presented based on Pearson correlations of backgroundsubtracted densitometric curves from denaturing gradient gelelectrophoresis. Stress value is 0.037 , $n=4$. 


\subsection{Isolation and Characterization of Cuticle-Attached Bacteria}

The isolation of culturable bacterial strains with high affinity to attach to the cuticle of $P$. penetrans baited in different rhizospheres and corresponding bulk soil resulted in 20 isolates with unique fingerprints, as characterized by $16 \mathrm{~S}$ rRNA gene sequencing (Table 1 , Figure S3). Nine bacterial species were isolated from the nematodes after the incubation in the suspension of bulk soil, while the diversity of isolates obtained after incubation of the nematodes in the rhizosphere suspensions was lower. The bacterial isolates belonged to Actinobacteria (Streptomyces, Pseudomonas, Microbacterium, Mycobacterium, Nocardia), Alphaproteobacteria (Rhizobium, Novosphingobium), Betaproteobacteria (Delftia, Alcaligenes), Gammaproteobacteria (Lysobacter), Sphingobacteria (Pedobacter), and Firmicutes (Bacillus, Staphylococcus).

Nine bacterial strains that were isolated from the cuticle of P. penetrans were tested for their attachment to the nematodes (Figure 5). Among these, only two strains, i.16 and i.35, showed a low attachment rate with less than 30 attached CFU per nematode, while all the other strains had a significantly higher attachment rate to P. penetrans than the negative control strain E. coli JM109 ( $p<0.0001$, Dunnett's test). The highest density of attached cells was observed for the bacterial isolates Microbacterium sp. i.14, Lysobacter capsici i.17, and Alcaligenes sp. i.37.

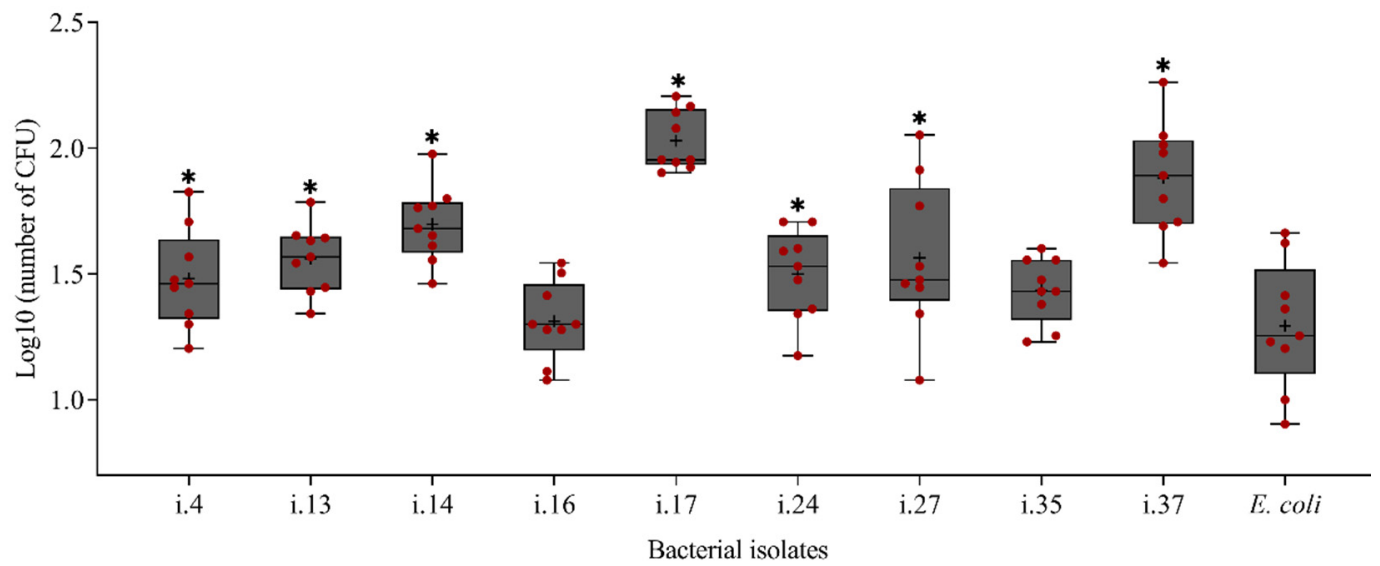

Figure 5. Attachment capacity of bacterial isolates from infective stages of Pratylenchus penetrans to the cuticle of P. penetrans. Nematodes were incubated in suspensions of the bacteria in water, washed on sterile sieves, and plated on R2A media. Escherichia coli JM109 was used as a negative control. Mean log transformed numbers of CFU are shown as (+) for each strain, the medians are shown as (-), whiskers indicate quartiles. Stars above whiskers indicate significant differences compared to the control E. coli (Dunnett's test, $n=9$ ).

\subsection{Effect of Cuticle-Attached Microbiomes on the Mortality of P. penetrans}

We tested the capacity of the nematode-attached microbiomes from rhizospheres of Ethiopian mustard, maize, and oat, and from the corresponding bulk soil to affect the mortality of infective stages of $P$. penetrans. After baiting nematodes in the soil suspension, cuticle-attached microbes per nematode ranged between 26 CFU for Ethiopian mustard rhizosphere and $93 \mathrm{CFU}$ for oat rhizosphere (Figure 6). The microbial attachment was significantly higher for oat rhizosphere and bulk soil compared to Ethiopian mustard rhizosphere. In the in vitro mortality assay, all attached microbiomes increased the percentage of dead nematodes compared to the control, where nematodes were incubated in sterile tap water (Figure 7). However, the numbers of dead nematodes were low, ranging from six nematodes killed by the microbiome from bulk soil to nine nematodes killed with the microbiome from the rhizosphere of Ethiopian mustard. The numbers of microorganisms attaching to nematodes in the different treatments did not correlate well with mortality. 


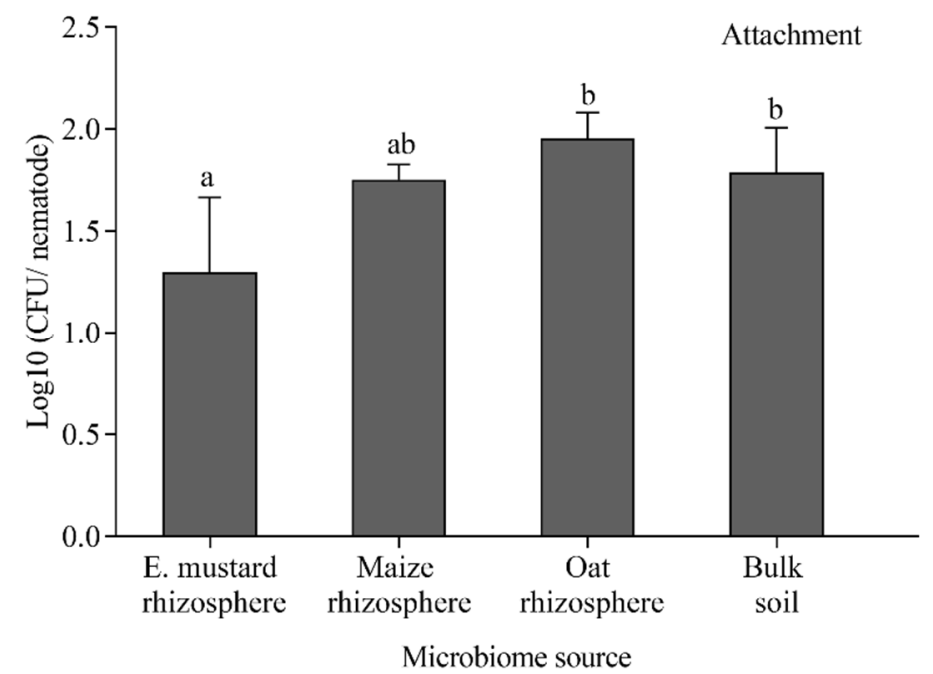

Figure 6. Number of microbes attached to infective stages of Pratylenchus penetrans after baiting in suspensions of soil from the rhizosphere of different crops or the corresponding bulk soil. Letters above bars indicate significant differences among treatments (Tukey's test, $p<0.05, n=12$ ). Error bars represent standard deviations. E. mustard: Ethiopian mustard.

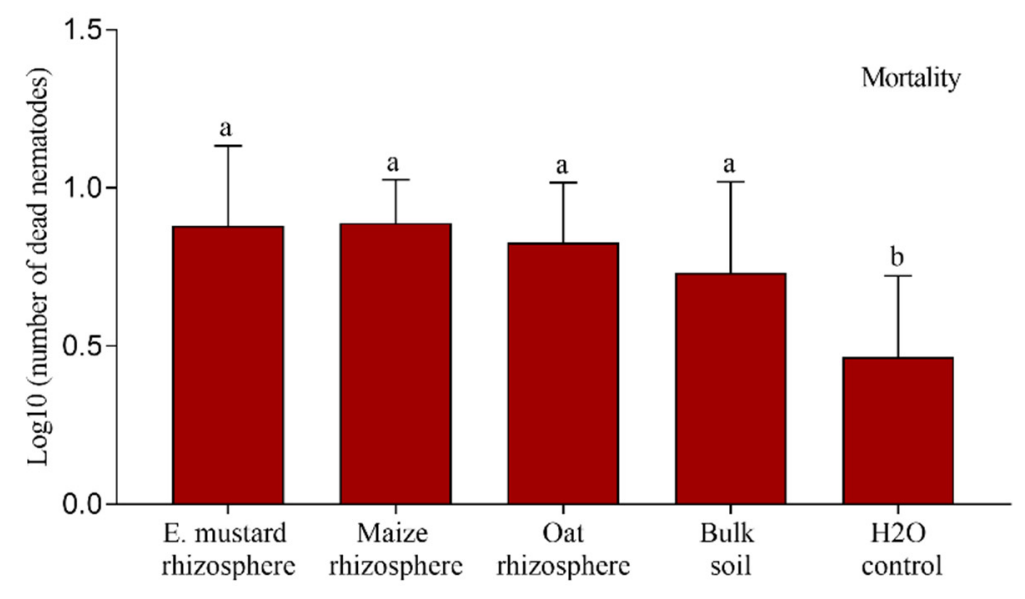

Microbiome source

Figure 7. Effect of microbiomes from the rhizosphere of different crops or the corresponding bulk soil on mortality of Pratylenchus penetrans. Letters above bars indicate significant differences among treatments (Tukey's test, $p<0.05, n=12$ ). Error bars represent standard deviations.

\subsection{Effect of Cuticle-Attached Bacterial Isolates on the Mortality of P. penetrans}

To monitor the nematicidal activity of bacteria isolated from the cuticle of $P$. penetrans, nematodes were incubated in suspensions of twenty different bacterial isolates over a 48 -h period. The effects on nematode survival were compared to sterile tap water as a negative control. The nematicidal effect of the bacteria was highly variable, ranging from less than $10 \%$ for four strains up to $95 \%$ mortality for Bacillus cereus i.24 (Figure 8). The latter had a significantly higher efficiency than the well-studied antagonistic strain Rhizobium etli G12 [30] (83.5\% mortality on average). Isolate L. capsici i.17 also efficiently antagonized P. penetrans, leading to $79.5 \%$ mortality (Figure 8 ). 


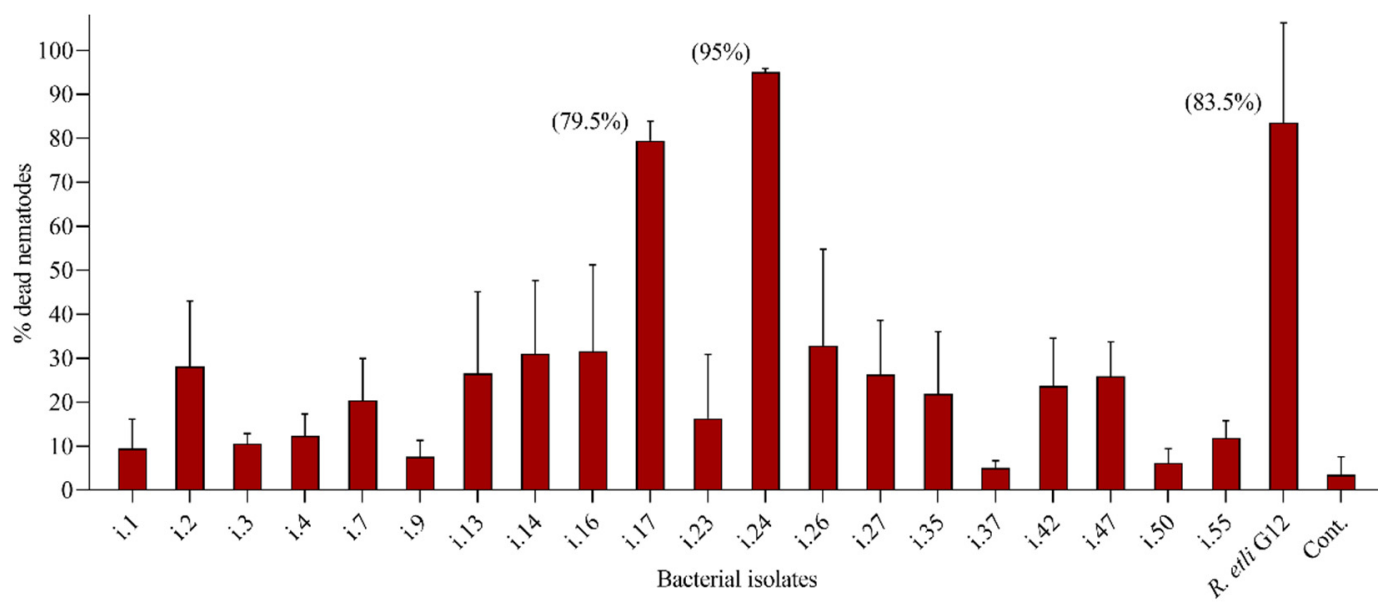

Figure 8. Effect of the nematode-isolated bacterial isolates on mortality of Pratylenchus penetrans after attachment to the cuticle. Cont.: negative control in sterile tap water. Error bars represent standard deviations, $n=3$.

\subsection{Effects of Root Exudates on the Attachment of Bacteria}

Differences in the microbiome structure on the cuticle of P. penetrans were associated with differences in the rhizosphere microbiome of different plant species. We wanted to test whether differences in root exudates of the plant species also contribute to differential attachment of microbes by changing the surface of the nematode. Surface-sterilized P. penetrans were exposed to sterile filtered root exudates from maize, soybean, or tomato. Sterilized tap water or an auxin solution served as control. Subsequently, the nematodes were baited in a bulk soil suspension overnight, washed, and the attached microbiome was studied by DGGE fingerprinting (Figures S4 and S5). Overall, pre-incubation of nematodes in the different root exudates or in an auxin solution did not significantly affect the composition of bacterial or fungal species that attached to the nematode surface in soil suspension. However, some additional bands in the bacterial DGGE profiles indicated bacterial species that specifically attached to the cuticle of those nematodes, which were pretreated with maize or soybean exudates (bands marked by an arrow in Figure S4). These differences were less notable for the attached fungal communities (Figure S5).

However, baiting of the differently conditioned nematodes in a suspension of the bacterial strain Microbacterium sp. i.14 resulted in a significantly reduced attachment of the bacteria to the cuticle of $P$. penetrans that was treated with exudates from soybean or maize roots compared to the other treatments (Figure 9). This suggested an effect on the cuticle structure by some plant-specific components of the root exudates. Auxin at a $1 \mu \mathrm{M}$ concentration did not induce cuticle changes. Exposure to exudates from tomato roots resulted in a trend for reduced attachment of strain i.14 that was not statistically significant compared to the water control using Tukey's test. 


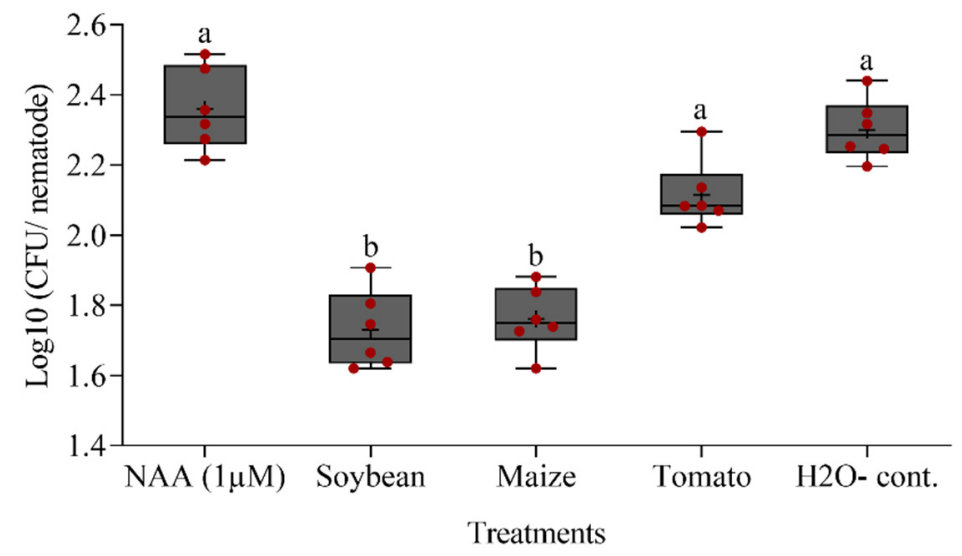

Figure 9. Effect of pre-incubation of $P$. penetrans in the root exudates of soybean, maize, or tomato on the attachment of the bacterial strain Microbacterium sp. i.14 to the surface of P. penetrans. Auxin (NAA) and sterile water were used as controls. Letters indicate significant differences among treatments (Tukey test, $p<0.05, n=6$ ). Medians are shown as $(-)$, whiskers indicate quartiles.

\section{Discussion}

\subsection{Plants Govern the Microbiome Associated with the Cuticle of P. penetrans in the Rhizosphere}

In a previous study, the rhizosphere microbial communities of maize, but not tomato, protected plants better against nematode attack than the microbial community from bulk soil [11]. As cuticle-attached microbes can affect the root invasion of nematodes [16,25,31,32], we investigated whether shifts in soil microbial communities induced by different plant species led to a different set of microbes attaching to the phytonematode species P. penetrans. DGGE fingerprints of fungal ITS fragments and bacterial 16S rRNA genes showed that the plant species determined which microbes attached to the cuticle. The microbial community structure in the rhizosphere was highly dependent on the plant species. This is consistent with several studies that emphasized the importance of plant species and soil type in the community structure of rhizosphere microorganisms [8]. The portion of bacteria and fungi that attached to P. penetrans after incubation in the soil suspensions of bulk soil and the different rhizosphere soils was very small in comparison to the total soil microbial communities. This means that the attachment of soil microorganisms to the nematodes is very specific and selective, and relies on the soil type and the nematode species $[16,30]$. In addition, the structure of the nematode-attached microbiome was very different depending on the rhizosphere type. This was especially obvious for nematodeattached fungi.

Given that nematodes migrate from bulk soil targeting their host plants, several factors can contribute to the establishment of the attached microbiome, which in turn can determine the nematode's behavior and interaction with the host plant. In the rhizosphere, microbial diversity is less than in bulk soil while specific microbial species are much more active and relatively more abundant due to the selection by root exudates [33]. Nematodes can modify their behavior on the basis of plant signals such as phytohormones that are present in root exudates. These may trigger rapid changes in the surface structure of plantparasitic nematodes [34,35]. This kind of change could be a reflection of the regulation of cuticle encoding genes leading to the preferential attachment of specific microbial species. For instance, the attachment of endospores of the nematophagous bacterium Pasteuria was found to be increased in response to root exudates, depending on the plant species and the presence of other soil microorganisms [21,22]. Nematodes modify their surface coat by producing surface proteins that mimic the ones produced by the host to counteract the host plant defense and escape from host detection [36,37].

In parallel, microbes that reside in the root-soil interface have evolved different means to enable them to navigate, respond, and bind to their hosts. For instance, soil bacteria move towards their host via multiple cellular chemotaxis and chemoreceptor encoding genes, 
which were found to be enriched in the rhizosphere compared to bulk soil in response to gradients of compounds derived from the host plant. Several types of chemotaxis signaling in beneficial bacteria, which promote motility through flagella and pili, are prevalent in the rhizosphere $[38,39]$. Adhesion factors in microbes that are stimulated in response to plant signals may determine the specific binding to the cuticle of nematodes. Bacteria and fungi bind to biomaterials through a wide variety of surface proteins, like adhesins or filaments that decorate the bacterial cell with appendages. For instance, the adhesion of Azospirillum brasilense was found to be affected by plant species specific compounds. The major outer membrane protein (MOMP) of $A$. brasilense had a stronger adhesion to the membrane-immobilized roots of cereals than to legumes or tomato extracts [40]. In light of this, our results demonstrate that plant specific root exudates and the microbiome in the rhizosphere determine the microbiome associated with the cuticle of the nematode directly before root invasion. This in turn might affect their fitness and invasion into the root. Consequently, deciphering the molecular interaction network of plant, nematode, and microbes will eventually lead to knowledge-based control of plant-parasitic nematodes.

\subsection{Effects of Nematode-Attached Microbiome on Nematode Fitness}

Using a culture-dependent approach, we isolated bacterial strains that specifically attached to $P$. penetrans in the rhizospheres of soybean, maize, and tomato, or in bulk soil. The ability of the isolates to attach to P. penetrans was confirmed in re-attachment experiments where only two strains showed attachment rates as low as that of the control strain E. coli, which was demonstrated to have a low affinity to attach to the cuticle [41]. The most prominent strains that highly attached to P. penetrans were assigned to the genera Streptomyces, Pseudomonas, Microbacterium, Mycobacterium, Rhizobium, Lysobacter, Alcaligenes, and Bacillus based on 16S rRNA sequence analysis. All of these bacterial genera have been frequently reported to antagonize RLN or root-knot nematodes [42-51]. Several isolated strains showed higher nematicidal effects in vitro than the well-known positive control R. etli G12, including B. subtilis and L. capsici. Siddiqui and Mahmood [50] proposed that non-parasitic rhizobacteria can antagonize nematodes by the production of specific toxic metabolites and by alteration of root exudates. For instance, two toxic compounds, fervenulin and 6,8-dixydroxy-3-methylisocoumarin, that were isolated from a strain of Streptomyces sp., were able to antagonize Meloidogyne incognita in vitro by impeding egg hatch and by accelerating J2 mortality [52]. In addition, both B. cereus S2 and its secondary metabolite sphingosine were lethal for Caenorhabditis elegans and $M$. incognita in vitro or by inducing systemic resistance in plants [45]. In fact, evidence is accumulating that many rhizobacteria, including Bacillus spp., go as far as triggering expression of PTI-responsive defense genes in plants that hinder nematode penetration and development [32,53-58]. With that in mind, the ability of isolated strains in our study to function in nematode suppression by inducing systemic resistance in plants should be further investigated.

It has been proposed that rhizo-microbiomes show high efficiency in nematode control for two reasons: (1) their relative abundance and activity are generally higher in the rhizosphere than in the surrounding soil [9,10]; and (2), the phytonematodes reside in close proximity of the root, thus sharing the rhizosphere habitat with plant-associated microbes [59]. In our study, the nematode mortality induced by the attached microbiome from rhizospheres of Ethiopian mustard, maize and oat, and from bulk soil was rather low, and was independent from the number of attached bacterial cells on the nematode after a 24-h incubation. While higher microbial diversity and species richness in the rhizosphere would presumably lead to a higher nematode mortality [60], we think that the species evenness of microorganisms that managed to attach to P. penetrans was low and insufficient to cause a high mortality effect, as it was the case with single bacterial isolates. Furthermore, some studies showed that microorganisms alone did not affect nematode mortality and movements in the absence of the host plant, but they prevented nematode attraction and performance on the roots in the case where the plant was present $[25,61]$. 


\subsection{Role of Root Exudates in Microbial Attachment and Suppression of P. penetrans}

Root exudates contain molecular cues that are of importance for the cross talk between plants, microorganisms, and nematodes [15]. They were reported to directly induce changes in the nematode's surface composition, which was measured by the nematode's ability to absorb lipid probes after exposure to different environmental cues $[17,34,35]$. Potato root diffusates have shown to increase the uptake of the lipid probe AF18 by Globodera rostochiensis [34], while tomato root diffusates increased the surface lipophilicity of M. incognita [35]. Phytohormones, such as kinetin and auxin, also induced differential changes in surface lipophilicity [34]. This prompted us to investigate whether the changes in surface composition of P. penetrans by different root exudates would affect the binding of the bacterial isolate Microbacterium sp. i.14, which showed a high rate of attachment to this nematode species. Interestingly, we found that the attachment of this isolate was reduced by root exudates from soybean and maize, but not from tomato. The increased bacterial binding after exposure to tomato root exudates reflected the high permissiveness of this plant to nematode attack. Yang et al. [62] found negative effects of root exudates from both resistant and highly susceptible tomato cultivars on the egg hatch and J2 mortality of M. incognita, but the $\mathrm{J} 2$ attraction to the roots was promoted by the latter.

\section{Conclusions}

In our study, we found that the host plant plays an important role in shaping the nematode-microbiome association. Microbial taxa or species that are enriched in the rhizosphere can affect the fitness of parasitic nematodes. Each plant species recruits its associated microbial species based on the soil type and availability of diverse taxa of microorganisms that, in turn, support suppressiveness against plant-parasitic nematodes. Thus, the plant-soil feedback determined by the interactions of root exudates, nematodeattached microbes in the rhizosphere, and the nematode cuticle might be important to understand soil suppressiveness against plant-parasitic nematodes.

Supplementary Materials: The following are available online at https:/ /www.mdpi.com/2076-2 607/9/4/679/s1, Table S1: Percent dissimilarity of bacterial or fungal communities attached to the cuticle of Pratylenchus penetrans that were incubated in soil suspensions from different rhizospheres or bulk soil, or non-attached microbial communities in the respective soil suspension; Table S2: Identification and frequency of fungal and bacterial species associated with Pratylenchus penetrans after baiting in suspensions of bulk soil or different rhizosphere soils; Figure S1: DGGE profiles of fungal ITS fragments amplified from DNA of bulk soil and rhizospheres of maize, soybean and tomato plants grown in the same soil; Figure S2: DGGE profiles of bacterial 16S rRNA fragment fragments amplified from DNA of bulk soil and rhizospheres of maize, soybean and tomato plants grown in the same soil; Figure S3: Box-PCR fingerprints of bacterial strains isolated from Pratylenchus penetrans cuticle after incubation in bulk soil or the rhizosphere soil of maize, tomato, or soybean; Figure S4: Effect of pre-incubation of Pratylenchus penetrans in root exudates of soybean, maize, or tomato on the bacterial community attached to the cuticle; Figure S5: Effect of pre-incubation of Pratylenchus penetrans in root exudates of soybean, maize, or tomato on the fungal community attached to the cuticle.

Author Contributions: A.E. and H.H. designed and conceived the idea of the experiments. A.E. performed the experiment of microbiome associated with RLN as affected by plant species. A.E. isolated and characterized bacteria and fungi associated with P. penetrans cuticle. A.E. and O.T. analyzed the biological effects of nematode-attached microbiome on nematode fitness. A.E. and O.T. investigated the effect of root exudates on microbial attachment to P. penetrans. A.E. and O.T. wrote the manuscript. A.E. created and edited the figures and tables. A.E. and H.H. performed the statistical analysis. A.E. and H.H. revised the final version of the manuscript. All authors have read and agreed to the published version of the manuscript.

Funding: This research was funded by the German Research Foundation (Deutsche Forschungsgemeinschaft, DFG), grant EL1038/2-1. OT was funded by the DFG grant HE6957/1-1.

Institutional Review Board Statement: Not applicable. 
Informed Consent Statement: Not applicable.

Data Availability Statement: All materials, isolates and clones culture stocks are available at Institute for Epidemiology and Pathogen Diagnostics, Julius Kühn Institute (JKI), Braunschweig, Germany upon request. DNA sequences of fungal ITS and bacterial 16S rRNA gene fragments were deposited in NCBI GenBank with accession numbers MN332046 to MN332063 and MW326933 to MW326970.

Acknowledgments: We thank Elvira Woldt and Kirsten Löhr for excellent technical assistance. Thanks, are also given to Doreen Babin, Rasha Haj Nuaima, and Xorla Kanfra for their help with the DGGE analyses.

Conflicts of Interest: The authors declare no conflict of interest.

\section{References}

1. Jones, J.T.; Haegeman, A.; Danchin, E.G.J.; Gaur, H.S.; Helder, J.; Jones, M.G.K.; Kikuchi, T.; Manzanilla-López, R.; Palomares-Rius, J.E.; Wesemael, W.M.L.; et al. Top 10 plant-parasitic nematodes in molecular plant pathology. Mol. Plant Pathol. 2013, 14, 946-961. [CrossRef] [PubMed]

2. Fosu-Nyarko, J.; Jones, M.G. Advances in understanding the molecular mechanisms of root lesion nematode host interactions. Annu. Rev. Phytopathol. 2016, 54, 253-278. [CrossRef]

3. Topalović, O.; Bredenbruch, S.; Schleker, A.S.S.; Heuer, H. Microbes attaching to endoparasitic phytonematodes in soil trigger plant defense upon root penetration by the nematode. Front. Plant Sci. 2020, 11, 138. [CrossRef] [PubMed]

4. Topalović, O.; Heuer, H. Plant-nematode interactions assisted by microbes in the rhizosphere. Curr. Issues Mol. Biol. 2019, 30, 75-88. [CrossRef] [PubMed]

5. Topalović, O.; Hussain, M.; Heuer, H. Plants and associated soil microbiota cooperatively suppress plant-parasitic nematodes. Front. Microbiol. 2020, 11, 313. [CrossRef] [PubMed]

6. Zilber-Rosenberg, I.; Rosenberg, E. Role of microorganisms in the evolution of animals and plants: The hologenome theory of evolution. FEMS Microbiol. Rev. 2008, 32, 723-735. [CrossRef]

7. Rosenberg, E.; Zilber-Rosenberg, I. The hologenome concept of evolution after 10 years. Microbiome 2018, 6, 1-14. [CrossRef]

8. Sánchez-Cañizares, C.; Jorrín, B.; Poole, P.S.; Tkacz, A. Understanding the holobiont: The interdependence of plants and their microbiome. Curr. Opin. Microbiol. 2017, 38, 188-196. [CrossRef]

9. Bulgarelli, D.; Rott, M.; Schlaeppi, K.; Van Themaat, E.V.L.; Ahmadinejad, N.; Assenza, F.; Rauf, P.; Huettel, B.; Reinhardt, R.; Schmelzer, E.; et al. Revealing structure and assembly cues for Arabidopsis root-inhabiting bacterial microbiota. Nat. Cell Biol. 2012, 488, 91-95. [CrossRef]

10. Lundberg, D.S.; Lebeis, S.L.; Paredes, S.H.; Yourstone, S.; Gehring, J.; Malfatti, S.; Tremblay, J.; Engelbrektson, A.; Kunin, V.; Del Rio, T.G.; et al. Defining the core Arabidopsis thaliana root microbiome. Nat. Cell Biol. 2012, 488, 86-90. [CrossRef] [PubMed]

11. Elhady, A.; Adss, S.; Hallmann, J.; Heuer, H. Rhizosphere microbiomes modulated by pre-crops assisted plants in defense against plant-parasitic nematodes. Front. Microbiol. 2018, 9, 1133. [CrossRef] [PubMed]

12. Fierer, N.; Jackson, R.B. The diversity and biogeography of soil bacterial communities. Proc. Natl. Acad. Sci. USA 2006, 103, 626-631. [CrossRef] [PubMed]

13. Haichar, F.E.Z.; Santaella, C.; Heulin, T.; Achouak, W. Root exudates mediated interactions belowground. Soil Biol. Biochem. 2014, 77, 69-80. [CrossRef]

14. Bertin, C.; Yang, X.; Weston, L.A. The role of root exudates and allelochemicals in the rhizosphere. Plant Soil 2003, $256,67-83$. [CrossRef]

15. Bais, H.P.; Weir, T.L.; Perry, L.G.; Gilroy, S.; Vivanco, J.M. The role of root exudates in rhizosphere interactions with plants and other organisms. Annu. Rev. Plant Biol. 2006, 57, 233-266. [CrossRef]

16. Adam, M.; Westphal, A.; Hallmann, J.; Heuer, H. Specific microbial attachment to root knot nematodes in suppressive soil. Appl. Environ. Microbiol. 2014, 80, 2679-2686. [CrossRef]

17. Davies, K.G.; Curtis, R.H.C. Cuticle surface coat of plant-parasitic nematodes. Annu. Rev. Phytopathol. 2011, $49,135-156$. [CrossRef]

18. Danks, C.; Davies, K. Carbohydrate/Protein interactions between the cuticle of infective juveniles of Meloidogyne incognita and spores of the obligate hyperparasite Pasteuria penetrans. Nematology 1993, 39, 53-64. [CrossRef]

19. Grenache, D.G.; Caldicott, I.; Albert, P.S.; Riddle, D.L.; Politz, S.M. Environmental induction and genetic control of surface antigen switching in the nematode Caenorhabditis elegans. Proc. Natl. Acad. Sci. USA 1996, 93, 12388-12393. [CrossRef]

20. Olsen, D.P.; Phu, D.; Libby, L.J.M.; Cormier, J.A.; Montez, K.M.; Ryder, E.F.; Politz, S.M. Chemosensory control of surface antigen switching in the nematode Caenorhabditis elegans. Genes Brain Behav. 2007, 6, 240-252. [CrossRef]

21. Liu, C.; Timper, P.; Ji, P.; Mekete, T.; Joseph, S. Influence of root exudates and soil on attachment of Pasteuria penetrans to Meloidogyne arenaria. J. Nematol. 2017, 49, 304-310. [CrossRef]

22. Singh, J.; Kumar, M.U.; Walia, R.K. Influence of plant root exudates on the adherence of Pasteuria penetrans endospores. Nematology 2014, 16, 121-124. [CrossRef] 
23. Bell, C.A.; Lilley, C.J.; McCarthy, J.; Atkinson, H.J.; Urwin, P.E. Plant-parasitic nematodes respond to root exudate signals with host-specific gene expression patterns. PLoS Pathog. 2019, 15, e1007503. [CrossRef] [PubMed]

24. Duarte, A.; Maleita, C.; Abrantes, I.; Curtis, R. Tomato root exudates induce transcriptional changes of Meloidogyne hispanica genes. Phytopathol. Mediterr. 2015, 54, 104-108. [CrossRef]

25. Topalović, O.; Elhady, A.; Hallmann, J.; Richert-Pöggeler, K.R.; Heuer, H. Bacteria isolated from the cuticle of plant-parasitic nematodes attached to and antagonized the root-knot nematode Meloidogyne hapla. Sci. Rep. 2019, 9, 11477. [CrossRef]

26. Engelen, B.; Meinken, K.; Von Wintzingerode, F.; Heuer, H.; Malkomes, H.-P.; Backhaus, H. Monitoring impact of a pesticide treatment on bacterial soil communities by metabolic and genetic fingerprinting in addition to conventional testing procedures. Appl. Environ. Microbiol. 1998, 64, 2814-2821. [CrossRef] [PubMed]

27. Weinert, N.; Meincke, R.; Gottwald, C.; Heuer, H.; Gomes, N.C.M.; Schloter, M.; Berg, G.; Smalla, K. Rhizosphere communities of genetically modified zeaxanthin-accumulating potato plants and their parent cultivar differ less than those of different potato cultivars. Appl. Environ. Microbiol. 2009, 75, 3859-3865. [CrossRef]

28. Kropf, S.; Heuer, H.; Grüning, M.; Smalla, K. Significance test for comparing complex microbial community fingerprints using pairwise similarity measures. J. Microbiol. Methods 2004, 57, 187-195. [CrossRef] [PubMed]

29. Versalovic, J.; Schneider, M.; de Bruijn, F.J.; Lupski, J.R. Genomic fingerprinting of bacteria using repetitive sequence based PCR (rep-PCR). Methods Mol. Cell. Biol. 1998, 5, 25-40.

30. Elhady, A.; Giné, A.; Topalovic, O.; Jacquiod, S.; Sørensen, S.J.; Sorribas, F.J.; Heuer, H. Microbiomes associated with infective stages of root-knot and lesion nematodes in soil. PLOS ONE 2017, 12, e0177145. [CrossRef]

31. Quentin, M.; Eabad, P.; Efavery, B. Plant parasitic nematode effectors target host defense and nuclear functions to establish feeding cells. Front. Plant Sci. 2013, 4, 53. [CrossRef]

32. Topalović, O.; Heuer, H.; Reineke, A.; Zinkernagel, J.; Hallmann, J. Antagonistic role of the microbiome from a Meloidogyne hapla-suppressive soil against species of plant-parasitic nematodes with different life strategies. Nematology 2019, $22,75-86$. [CrossRef]

33. Poole, P. Shining a light on the dark world of plant root-microbe interactions. Proc. Natl. Acad. Sci. USA 2017, 114, 4281-4283. [CrossRef]

34. Akhkha, A.; Kusel, J.; Kennedy, M.; Curtis, R. Effects of phytohormones on the surfaces of plant-parasitic nematodes. Parasitol. 2002, 125, 165-175. [CrossRef]

35. De Mendoza, M.E.L.; Modha, J.; Roberts, M.C.; Curtis, R.; Kusel, J.R. Changes in the lipophilicity of the surfaces of Meloidogyne incognita and Haemonchus contortus during exposure to host signals. Parasitology 2000, 120, 203-209. [CrossRef]

36. Ali, M.A.; Anjam, M.S.; Nawaz, M.A.; Lam, H.-M.; Chung, G. Signal transduction in plant-nematode interactions. Int. J. Mol. Sci. 2018, 19, 1648. [CrossRef] [PubMed]

37. Lok, J.B. Signaling in parasitic nematodes: Physicochemical communication between host and parasite and endogenous molecular transduction pathways governing worm development and survival. Curr. Clin. Microbiol. Rep. 2016, 3, 186-197. [CrossRef] [PubMed]

38. Scharf, B.E.; Hynes, M.F.; Alexandre, G.M. Chemotaxis signaling systems in model beneficial plant-bacteria associations. Plant Mol. Biol. 2016, 90, 549-559. [CrossRef] [PubMed]

39. Wuichet, K.; Zhulin, I.B. Origins and diversification of a complex signal transduction system in prokaryotes. Sci. Signal. 2010, 3, ra50. [CrossRef] [PubMed]

40. Burdman, S.; Dulguerova, G.; Okon, Y.; Jurkevitch, E. Purification of the major outer membrane protein of Azospirillum brasilense, its affinity to plant roots, and its involvement in cell aggregation. Mol. Plant Microbe Interact. 2001, 14, 555-561. [CrossRef]

41. Maghodia, A.; Spiegel, Y.; Sela, S. Interactions between Escherichia coli and the plant-parasitic nematode Meloidogyne javanica. J. Appl. Microbiol. 2008, 105, 1810-1816. [CrossRef]

42. Rosso, M.N.; Jones, J.T.; Abad, P. RNAi and functional genomics in plant parasitic nematodes. Annu. Rev. Phytopathol. 2009, 47, 207-232. [CrossRef]

43. Chen, J.; Moore, W.H.; Yuen, G.Y.; Kobayashi, D.; Caswell-Chen, E.P. Influence of Lysobacter enzymogenes strain C3 on nematodes. J. Nematol. 2006, 38, 233-239. [PubMed]

44. Dicklow, B.M.; Acosta, N.; Zuckerman, B.M. A novel Streptomyces species for controlling plant-parasitic nematodes. J. Chem. Ecol. 1993, 19, 159-173. [CrossRef] [PubMed]

45. Gao, H.; Qi, G.; Yin, R.; Zhang, H.; Li, C.; Zhao, X. Bacillus cereus strain S2 shows high nematicidal activity against Meloidogyne incognita by producing sphingosine. Sci. Rep. 2016, 6, 28756. [CrossRef] [PubMed]

46. Lee, Y.S.; Park, Y.S.; Anees, M.; Kim, Y.C.; Kim, Y.H.; Kim, K.Y. Nematicidal activity of Lysobacter capsici YS1215 and the role of gelatinolytic proteins against root-knot nematodes. Biocontrol Sci. Technol. 2013, 23, 1427-1441. [CrossRef]

47. Lee, Y.S.; Anees, M.; Hyun, H.N.; Kim, K.Y. Biocontrol potential of Lysobacter antibioticus HS124 against the root-knot nematode, Meloidogyne incognita, causing disease in tomato. Nematology 2013, 15, 545-555. [CrossRef]

48. Samac, D.A.; Kinkel, L.L. Suppression of the root-lesion nematode (Pratylenchus penetrans) in alfalfa (Medicago sativa) by Streptomyces spp. Plant Soil 2001, 235, 35-44. [CrossRef]

49. Shan, S.; Wang, W.; Song, C.; Wang, M.; Sun, B.; Li, Y.; Fu, Y.; Gu, X.; Ruan, W.; Rasmann, S. The symbiotic bacteria Alcaligenes faecalis of the entomopathogenic nematodes Oscheius spp. exhibit potential biocontrol of plant- and entomopathogenic fungi. Microb. Biotechnol. 2019, 12, 459-471. [CrossRef] 
50. Siddiqui, Z.; Mahmood, I. Role of bacteria in the management of plant parasitic nematodes: A review. Bioresour. Technol. 1999, 69, 167-179. [CrossRef]

51. Wei, J.-Z.; Siehl, D.L.; Hou, Z.; Rosen, B.; Oral, J.; Taylor, C.G.; Wu, G. An Enterotoxin-Like Binary Protein from Pseudomonas protegens with Potent Nematicidal Activity. Appl. Environ. Microbiol. 2017, 83, 00942-17. [CrossRef] [PubMed]

52. Ruanpanun, P.; Laatsch, H.; Tangchitsomkid, N.; Lumyong, S. Nematicidal activity of fervenulin isolated from a nematicidal actinomycete, Streptomyces sp. CMU-MH021, on Meloidogyne incognita. World J. Microbiol. Biotechnol. 2010, 27, 1373-1380. [CrossRef] [PubMed]

53. Van Peer, R.; Niemann, G.J.; Schippers, B. Induced resistance and phytoalexin accumulation in biological control of Fusarium wilt of carnation by Pseudomonas sp. strain WCS417r. Phytopathology 1991, 81, 728-734. [CrossRef]

54. Adam, M.; Heuer, H.; Hallmann, J. Bacterial antagonists of fungal pathogens also control root-knot nematodes by induced systemic resistance of tomato plants. PLoS ONE 2014, 9, e90402. [CrossRef]

55. Reitz, M.; Oger, P.; Farrand, S.K.; Hallmann, J.; Meyer, A.; Sikora, R.A.; Niehaus, K. Importance of the O-antigen, core-region and lipid A of rhizobial lipopolysaccharides for the induction of systemic resistance in potato to Globodera pallida. Nematology 2002, 4, 73-79. [CrossRef]

56. Siddiqui, I.A.; Shaukat, S.S. Systemic resistance in tomato induced by biocontrol bacteria against the root-knot nematode, Meloidogyne javanica is independent of salicylic acid production. J. Phytopathol. 2004, 152, 48-54. [CrossRef]

57. Selim, M.E.; Mahdy, M.E.; Sorial, M.E.; Dababat, A.A.; Sikora, R.A. Biological and chemical dependent systemic resistance and their significance for the control of root-knot nematodes. Nematology 2014, 16, 917-927. [CrossRef]

58. Martínez-Medina, A.; Fernandez, I.; Lok, G.B.; Pozo, M.J.; Pieterse, C.M.J.; Van Wees, S.C.M. Shifting from priming of salicylic acid- to jasmonic acid-regulated defences by Trichoderma protects tomato against the root knot nematode Meloidogyne incognita. New Phytol. 2017, 213, 1363-1377. [CrossRef]

59. Kerry, B.R. Rhizosphere interactions and the exploitation of microbial agents for the biological control of plant-parasitic nematodes. Annu. Rev. Phytopathol. 2000, 38, 423-441. [CrossRef]

60. Zhou, D.; Feng, H.; Schuelke, T.; De Santiago, A.; Zhang, Q.; Zhang, J.; Luo, C.; Wei, L. Rhizosphere microbiomes from root knot nematode non-infested plants suppress nematode infection. Microb. Ecol. 2019, 78, 470-481. [CrossRef]

61. Piśkiewicz, A.M.; De Milliano, M.J.K.; Duyts, H.; Van Der Putten, W.H. Plant ectoparasitic nematodes prefer roots without their microbial enemies. Plant Soil 2008, 316, 277-284. [CrossRef]

62. Yang, G.; Zhou, B.; Zhang, X.; Zhang, Z.; Wu, Y.; Zhang, Y.; Lü, S.; Zou, Q.; Gao, Y.; Teng, L. Effects of tomato root exudates on Meloidogyne incognita. PLoS ONE 2016, 11, e0154675. [CrossRef] [PubMed] 